\title{
Unusual Cause of Unilateral Epistaxis: Nasal Leech Infestation
}

\author{
'Ghimire A, ${ }^{2}$ Acharya A \\ ${ }^{1}$ Assistant Professor, Department of ENT; ${ }^{2}$ Assistant Professor, Department of Microbiology, B.P. Koirala Institute of Health Sciences Dharan \\ Nepal
}

\section{ABSTRACT}

Common causes for unilateral nasal bleeding in adults are benign or malignant tumors and deviated nasal septum. Here we present two cases of recurrent unilateral nasal bleeding due to leech infestation. Though it is not a common cause for nasal bleeding, a clinician should suspect leech infestation for a recurrent nasal bleeding specially in tropical countries like Nepal.

Key words: leech infestation, nasal bleeding, unilateral

\section{INTRODUCTION}

Epistaxis is a common complaint. The incidence of an episode of nasal bleeding during a life time has been described as approximately $60 \% .^{1}$ Epistaxis results from the interaction of factors that damage the nasal mucosal lining, affect the vessel walls, or alter the coagulability of the blood, and which may be categorized into environmental, local, systemic and medicationrelated. Unilateral epistaxis is commonly due to foreign bodies or benign or malignant neoplasms. Parasitic infestation is a rare cause, the most important being myiasis. Leech infestation has not been mentioned as a cause of epistaxis in standard textbooks. Sometimes, a diagnostic dilemma may occur, as in one of our cases. But in a country like Nepal, tropical regions, leech infestation should also be considered an important cause for unilateral epistaxis.. Here we present two cases of unilateral epistaxis due to leech infestation.

\section{CASE REPORTS:}

\section{CASE 1}

A sixty-three-year old male presented with a history of recurrent left-sided nasal bleeding for 5 months. The bleeding was intermittent and 2-5 ml per episode. At presentation his blood pressure was $130 / 96 \mathrm{~mm}$ $\mathrm{Hg}$. Anterior rhinoscopy did not reveal any nasal pathology that could have caused epistaxis. There was no active nasal bleeding and no bleeding point could be identified. Routine blood investigations were

\section{Correspondence:}

Dr. Anand Ghimire

Assistant Professor

Department of Otolaryngology \& Head-Neck Surgery

B.P. Koirala Institute of Health Sciences. Dharan

E-Mail: anand_ghi@yahoo.com 
normal. The coagulation profile was normal. Computed tomography of paranasal sinuses (CT-PNS) had already been done elsewhere and did not show any abnormality. He had already been treated with oxymetazoline nasal drops, antibiotics and systemic decongestants from other clinics. Endoscopic evaluation of the nasal cavity revealed a blackish mobile leech attached to the lateral aspect of the middle turbinate. The leech retracted into the deep part of the middle meatus when the endoscope was introduced. The leech was removed with forceps after applying a $10 \%$ lidocaine spray. The patient attended a follow-up after two weeks. He was totally asymptomatic.

\section{CASE 2}

A thirty-eight-year man presented with a history of recurrent, painless, left-side nasal bleeding for one month. The bleeding used to stop spontaneously. There was no history of trauma, high blood pressure or bleeding disorders. On anterior rhinoscopy of the left side, there was a blackish live worm on the middle turbinate. The first attempt of removal was unsuccessful because the worm retracted and disappeared. Then a $10 \%$ of lidocaine spray was administered into the nasal cavity to paralyze the worm. Five minutes later, anterior rhinoscopy was done. This time the worm was seen in the anterior part of the nose. (Figure 1) and was removed with forceps. It was black in color, measuring $5 \mathrm{~cm}$ in length and $0.5 \mathrm{~cm}$ in width (Figure 2). After a one-month of follow-up he was asymptomatic.

\section{DISCUSSION}

Leeches are annelids or segmented worms with a powerful clinging sucker at each end. Common species that can infest humans are Dinobdella ferox, Hirudinea granulose and Hirudinea viridis. ${ }^{2}$ Both aquatic and land leeches are known to attack humans. Leeches are generally found in puddles of water and streams. When water is drunk from these streams and from puddles, leeches can infest the human body; they can then be located anywhere in the upper respiratory tract from the nose to the larynx. They adhere to the mucosa with the anterior sucker and they live on blood here. Both of our cases used to drink water directly from the river and that may be the source of entry of the leech into the nasal cavity.

The saliva of the leech contains hirudin, which inhibits thrombin in the clotting process, and histamine-like substances which may cause continuous bleeding by preventing closure of capillaries. ${ }^{3}$ The leech saliva also has local anesthetic properties. That's why the wound caused by the leech is not painful. ${ }^{4}$

Epistaxis is a common problem and most of the time its cause is obvious. But nasal bleeding caused by leech infestation sometimes may cause a diagnostic dilemma as in our first case. This is because every corner of the nasal cavity can not be visualized easily and the leech inside the nose may retract to the areas which are difficult to visualize during anterior rhinoscopy. In such a situation, endoscopic evaluation of the nose is helpful. In our first case, the leech could not be seen until the endoscopy was done.

Respiration by the leech takes place through its body wall. It can be paralyzed with anesthetic agents like lidocaine. The suffocation caused by anesthetic agents causes the worm to migrate towards the surface and it also makes the attachment of the leech to the mucosa weak. It can then be removed easily. In both cases, we used $10 \%$ lidocaine spray to paralyze the worm before its removal.

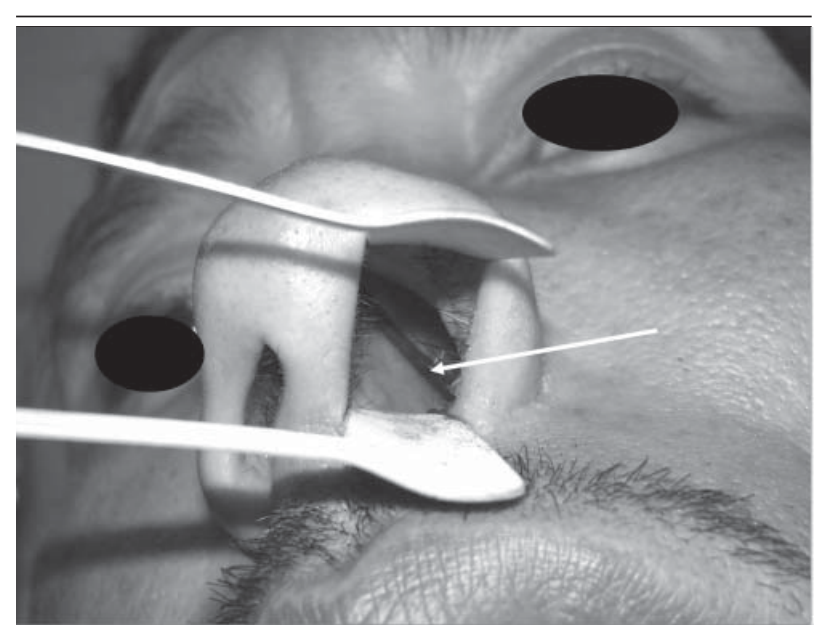

Figure 1. A live leech (White arrow) inside the left nostril revealed by anterior rhinoscopy.

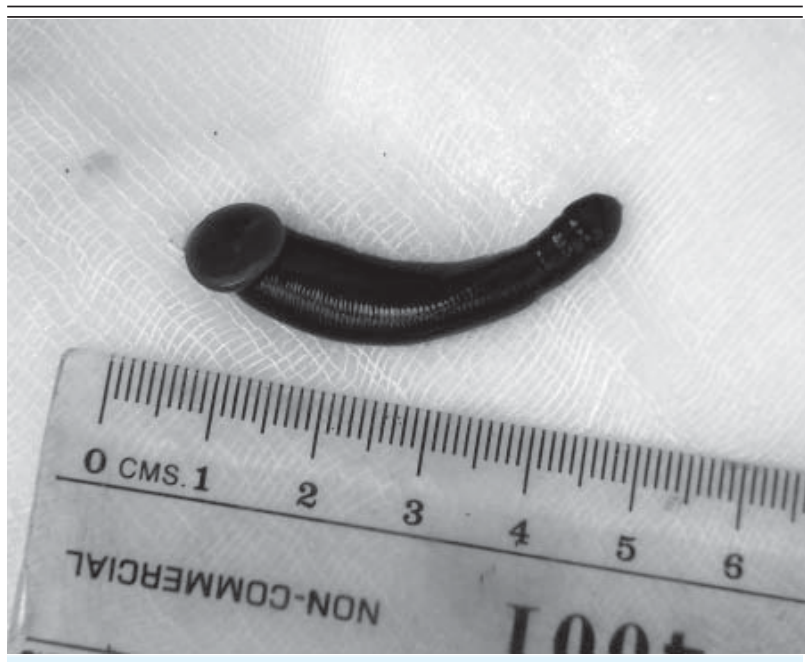

Figure 2. The leech recovered from the nasal cavity. 


\section{CONCLUSION}

Leech infestation should be considered in the differential diagnosis for epistaxis, particular in leech-endemic areas. Every attempt should be made to locate the source of epistaxis that does not respond to simple compression. Endoscopic evaluation of the nasal cavity is mandatory in recurrent epistaxis, particularly when the cause is not obvious.

\section{REFERRENCES}

1. Massick D. Tobin EJ. Epistaxis. In: Cummings CW, Flint PW, Harker LA, Haughey BH, Richardson MA, Robbins KT et al. Otolaryngology- Head \& Neck Surgery. 4th ed. Philadelphia: Elsevier Mosby; 2005. p.942-61.

2. Gangadharan S KS, Rajeshwari A. An unusual foreign body in the nose. Gujarat Journal of Otolaryngology and Head \& Neck Surgery. 2005;2:21-22

3. Faust EC, Russel PF, Jurg RC. Craig and Faust's Clinical Parasitology. 8th ed. Philadelphia: Lea \& Febiger; 1970. p.563-70.

4. Chow CK, Wong SS, Ho AC, Lau SK. Unilateral epistaxis after swimming in a stream. Hong Kong Med J 2005;11:110-2. 